Кобалава Ж.А., Троицкая Е.А., Толкачева В.В.

Федеральное государственное автономное бюАжетное образовательное учреждение высшего профессионального образования «Российский университет Аружбы народов» (РУАН), Москва, Россия

КОМБИНИРОВАННАЯ ТЕРАПИЯ АРТЕРИААЬНОЙ ГИПЕРТОНИИ С ИСПОАЬЗОВАНИЕМ ТРЕХКОМПОНЕНТНОЙ ФИКСИРОВАННОЙ КОМБИНАЦИИ АМАОАИПИНА, ИНААПАМИАА И ПЕРИНАОПРИАА АРГИНИНА В КАИНИЧЕСКОЙ ПРАКТИКЕ: ОРГАНИЗАЦИЯ

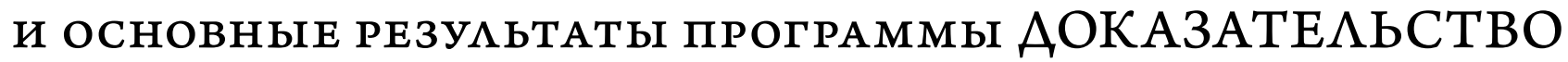

КАючевые слова: артериальная гипертония, тройная антигипертензивная терапия, фиксированная комбинация, аммодипин/индапамиА/периндоприка аргинин.

Ссылка для цичтиования: Кобалава Ж.А., Троицкая Е. А., Толкачева В. В. Комбинированная терапия артериальной гипертонии с использованием трехкомпонентной фиксированной комбинации амлодипина, индапамида и периндоприла аргинина в клинической практике: организация и основные результаты программы АОКАЗАТЕАЬСТВО. Кардиология. 2018;58(9):21-30.

Резюме

Цель исследования. Оценка антигипертензивной эффективности фиксированной комбинации амлодипин/индапамиА/перинАоприла аргинин у пациентов с артериальной гипертонией (АГ) в клинической практике. Материаль и методы. В науч-

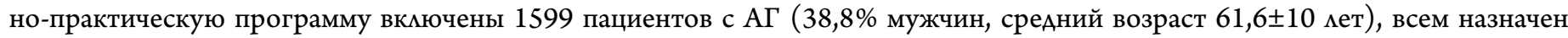
трипликсам в оАной из 4 возможных Аозировок на 3 мес. Основная изел: Аинамика клинического и амбулаторного АА при самоконтроле от визита 1 к визиту 4 и частота Аостижения целевого клинического артериального Аавления (АА) <140/90 мм рт. ст. через 3 мес. Аополнительные цели: частота ответа на иечение, приверженность, безопасность. Результаты. Через 3 мес кли-

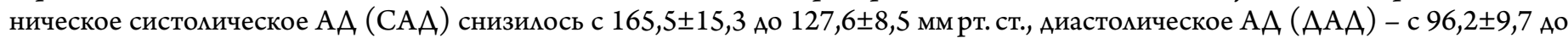

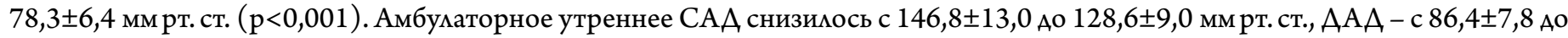

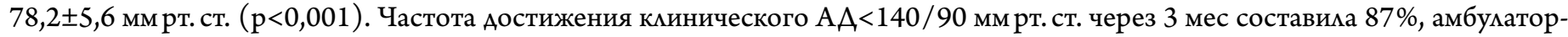
ного AA $<135 / 85$ мм рт. ст. - 68,1\%. Оценка приверженности к мечению увеличилась с $2,9 \pm 1,6$ Ао $5,1 \pm 1,0$ балма (p<0,001). Заключение. Применение трипликсама сопровожАается снижением клинического АА на 38/18 мм рт. ст. и быстрым Аостижением контроля АА у большинства больных через 3 мес мечения. Подтверждены хорошая переносимость и высокая безопасность препарата.

Kobalava Zh. D., Troitskaya E. A., Tolkacheva V.V. RUDN University, Moscow Russia

\title{
Combined Therapy of Arterial Hypertension With Triple Fixed-Dose Combination of Amlodipine/Indapamide/Perindopril Arginine in Real Clinical Practice: the Organization and the Main Results of The DOKAZATEL'STVO (Proof) Study
}

Keywords: arterial hypertension; triple antihypertensive therapy; fixed-dose combination; single-pill combination; amlodipine/indapamide/perindopril arginine.

For citation: Kobalava Zh.D., Troitskaya E.A., Tolkacheva V. V. Combined Therapy of Arterial Hypertension With Triple Fixed-Dose Combination of Amlodipine/Indapamide/Perindopril Arginine in Real Clinical Practice: the Organization and the Main Results of the DOKAZATEL'STVO (Proof) Study. Kardiologiia. 2018;58(9):21-30.

\section{SUMMARY}

Aim: to assess antihypertensive efficacy of the fixed-dose amlodipine/indapamide/perindopril arginine combination in hypertensive patients in real clinical setting. Methods. We included in the 3-month clinical program 1599 patients with arterial hypertension (AH) (38.8\% men, mean age 61.6 \pm 10 years). Primary outcomes were change of office and ambulatory (home blood pressure monitoring) systolic and diastolic blood pressure (SBP and DBP) from baseline to 3 months and rate of achievement 
of target $\mathrm{BP}<140 / 90 \mathrm{mmHg}$. Secondary outcomes included response to the therapy, adherence to treatment and safety. Results. By 3 months office BP decreased from $165.5 \pm 15.3 / 96.2 \pm 9.7$ to $127.6 \pm 8.5 / 78.3 \pm 6.4 \mathrm{mmHg}(\mathrm{p}<0.001)$; ambulatory BP - from $146.8 \pm 13.0 / 86.4 \pm 7.8$ to $128.6 \pm 9.0 / 78.2 \pm 5.6 \mathrm{~mm} \mathrm{Hg}(\mathrm{p}<0.001)$. Target office $\mathrm{BP}<140 / 90$ and ambulatory $\mathrm{BP}<135 / 85 \mathrm{mmHg}$ was achieved in 87 and $68.1 \%$ of patients, respectively. Adherence score increased from $2.9 \pm 1.6$ Ao $5.1 \pm 1.0$ ( $p<0.001$ ). Conclusion. Administration of a fixed-dose amlodipine/indapamide/perindopril arginine combination resulted in significant BP decrease and rapid achievement of target office BP in most patients. The combination was safe and well tolerated.

A ртериальная гипертония (АГ) остается оАним из главных факторов риска развития сердечнососуАистых осложнений (ССО) и смерти во всем мире, несмотря на успехи, Аостигнутые в обмасти антигипертензивной терапии (АГТ). Распространенность АГ в России составляет около 44\%, и ожидается продолжение увеличения этого показателя. Остается высокой и частота развития неконтролируемой АГ [1-3], а большинству пациентов Аля Аостижения контроля артериамьного Аавмения (АА) требуется комбинированная АГТ. ОАной из стратегий повышения эффективности терапии является назначение фиксированных комбинаций антигипертензивных препаратов [4-7]. Очевидно, что пациентам с АГ 2-3-й степени Амя Аостижения целевого AA необходима комбинация 2 препаратов и более, и часто 3 препаратов и более с различными механизмами Аействия; это нашло отражение в рекомендациях по мечению больных АГ [8-10]. В соответствии с рекоменАациями Европейского общества карАиологов комбинированная терапия является оптимальной стартовой стратегией у пациентов с АГ, а назначение трехкомпонентной комбинации у многих пациентов может стать следующим необходимым шагом в Аостижении целевого AA [11]. Комбинация блокатора ренин-ангиотензинальдостероновой системы с Аигидропиридиновым блокатором камьциевых канамов (БКК) и Аиуретиком, несомненно, явмяется рационацьной за счет синергизма антигипертензивного эффекта и взаимного уменьшения некоторых побочных эффектов препаратов отдельных классов [8]. Трипликсам (оригинальная комбинация «Servier») преАставмяет собой фиксированную комбинацию амлоАипина, инАапамиАа и периндоприла аргинина, обладающих Аоказанной эффективностью в отношении снижения АA, состояния эндотекия и некоторых жестких конечных точек (сердечно-сосудистая и общая смертность и серАечно-сосудистые события) [13-20]. Имеется широкая доказательная база Аанных о благоприятных эффектах отАельных компонентов трипликсама и их комбинаций, в том числе из отечественной киинической практики [21-23]. Аанные об эффективности и благоприятных эффектах трехкомпонентной комбинации аммодипина, индапамида и периндоприма аргинина накапливаются в послеАние годы. Так, в исслеАовании ADVANCE продемонстрировано снижение риска смерти от всех причин при добавлении амло-
Аипина к фиксированной комбинации периндоприла аргинин/индапамиА [20]. Антигипертензивная эффективность трехкомпонентной комбинации продемонстрирована в открытых наблюдательных исследованиях PAINT, PIANIST и PETRA [24-26]. Кроме того, эффективность и безопасность фиксированной комбинации амлоАипина, индапамиАа и периндоприла аргинина поАтвержАены в небольшом российском рандомизированном клиническом исследовании (РКИ) III фазы и украинском исследовании ТРИУМФ [27, 28]. Широкий спектр вариантов Аозировок трипликсама Аелает его уАобной фиксированной комбинацией Аля назначения больным АГ.

Программа АОКАЗАТЕ АЬСТВО была организована с целью изучения антигипертензивной эффективности и безопасности трипииксама и изменения приверженности к мечению при его назначении пациентам с АГ в клинической практике.

\section{Материамы и методы}

В научно-практической программе приняли участие 1599 пациентов с АГ. В качестве исследователей выступали терапевты и кардиологи поликлиник. Протокол Программы бым подготовлен на базе кафедры внутренних болезней с курсом карАиологии и функциональной Аиагностики ФГАОУ ВО «РУАН и согласован с комитетом по этике МеАицинского института «РУАН».

Основными цемями являлись оценка антигипертензивной эффективности препарата и частоты достижения контроля АА через 3 мес. Аополнительные цели включами изучение приверженности пациентов к мечению и безопасности препарата.

В программу вкмючали пациентов в возрасте 18 мет и старше с установменной эссенциальной АГ, подтвержАенной не менее 3 мес назаА. Не рекомендовалось включать пациентов с симптоматической АГ, хронической серАечной неАостаточностью (XCH) III-IV функционального класса (по NYHA), сахарным Аиабетом (СА) 1-го типа или декомпенсацией СА 2-го типа, тяжемой патологией печени и почек, находящихся на Аиализной терапии.

Трипииксам назначали после подписания пациентом формы информированного согласия. Препарат мог быть назначен не только пациентам с отсутствием контромя АГ на фоне преАшествующей АГТ, но и тем, у кого врач решах заменить эффективную свободную 
трехкомпонентную комбинацию указанных препаратов на фиксированную. Аозу трипииксама определял врач, выбирая из 4 возможных вариантов: амлодипин/индапамиА/ периндоприка аргинин 5/1,25/5 мг, 10/1,25/5 мг, 5/2,5/10 мг и 10/2,5/10 мг. Период наблюдения после визита включения составия 3 мес, в течение которых пациент трижды посещал врача - через 2 неА, 1 и 3 мес. В ходе визитов проводилось заполнение индивидуальной регистрационной карты (ИРК), измерение АА, частоты сердечных сокращений (ЧСС). Кроме того, на кажАом визите анацизировался Аневник самоконтроля АА, который пациенты заполняли в течение 6 Аней до посещения врача. На основании полученных Аанных принималось решение о возможности продолжения терапии и при необходимости корректировалась доза трипликсама. В ИРК, помимо значений клинического АА, вносики Аемографические Аанные (пол, возраст, рост, масса тела, индекс массы тела - ИМТ), имеющиеся факторы риска развития серАечно-сосудистых осложнений (ССО), антигипертензивную терапию помимо трипликсама, а также результаты мабораторных исследований за послеАние 3 мес при их наличии (гликемия, мипидный состав крови, уровень мочевой кислоты, функция почек, альбуминурия).

Аля киинического АА целевым уровнем считали $<140 /<90$ мм рт. ст., Аля амбулаторного -<135/<85 мм рт. ст. Аополнительно оценивали Аостижение «усиленных $\gg$ целевых уровней: <130/<80 мм рт. ст. Аля клинического АА.

КАиническое АА измеряли в ходе визита с помощью аускультативного ими осцимлометрического метода и полуавтоматического сфигмоманометра. ПереА проведением измерений пациент находился 3-5 мин в положении сиАя, выполняли не менее Авух измерений АА с интервалом 1-2 мин, в ИРК записывали среАнее значение Авух измерений [8-10].

Всем пациентам было рекомендовано проводить самоконтроль АА за 6 Аней до визита к врачу. Измерение проводили утром до приема антигипертензивных препаратов и вечером переА сном. Результаты измерения заносили в выАанный Аневник самоконтроля АА.

Приверженность к мечению оценивали на основании заполнения специального опросника из 6 вопросов на первом и послеАнем визитах. В случае ответа «нет» на все преАложенные вопросы приверженность оценивамась как хорошая, ответа «да» на 1-2 вопроса - как умеренная, ответа «Аа» на $\geq 3$ вопросов - как отсутствие приверженности. За кажАый ответ «нет» пациент получал 1 бамл, за каждый ответ «Аа» - 0. На завершающем визите врачам и пациентам было преАложено оценить эффективность мечения по 10-бамльной шкаме, гАе 0 соответствовац полной неудовлетворенности результатами мечения, а 10 бамлов - помной уАовлетворенности.
Основными критериями эффективности мечения являлись Аинамика клинического и амбулаторного систоиического (САА) и Аиастолического (ААА) АА от визита 1 к визиту 4 и частота достижения целевого АА. В качестве вторичных критериев эффективности оценивали число больных, Аостигших целевого САА и ААА, и чисмо больных, ответивших на мечение, т. е. тех, у кого САА и/ики ААА нормакизовались или снизикись хотя бы на 10 и/ или 5 мм рт. ст. соответственно. В ходе исследования регистрировали частоту нежелатемьных явлений.

Статистическая обработка полученных Аанных выполнена с использованием методов описательной статистики. Исходные характеристики анализирова$\Lambda и$ в выборке пациентов, начавших мечение; оценку эффективности терапии выполняли в выборке пациентов, выполнивших протокол. Аля сравнения изменения всех изучаемых параметров использовали критерий t Стьюдента в случае нормального распределения Аанных и непараметрический критерий Вилкоксона в случае ненормального распределения. Результаты преАставлены в виде $\mathrm{M} \pm \mathrm{SD}$ или в виде Ме (межквартильный интервац) соответственно. Аостоверными считали размичия при $\mathrm{p}<0,05$.

\section{Резумьтаты}

\section{Характеристика пациентов}

В программу включены 1599 больных АГ, основные клинико-демографические характеристики которых преАставлены в табл.1. Большинство пациентов имели избыточную массу тела или ожирение. Наиболее частыми факторами риска развития АГ были Аислипидемия и возраст, сопутствующими заболеваниями - ишемическая болезнь сердца (ИБС) и СА 2-го типа. Семейный анамнез АГ имелся у 77,8\% пациентов, ИБС - у 39,8\%. Уровень АА соответствовац 1-й степени повышения у $20 \%$ больных, 2-й степени - у 55,4\%, 3-й степени - у 23,3\%, у 1,3\% пациентов АА на момент вкАючения находилось в предемах целевых значений.

\section{АГТ до включения в программу}

ПереА включением АГТ получали 98,3\% больных: монотерапию - 185 (11,6\%), комбинированную 1386 (86,7\%). Наиболее часто назначаемыми классами антигипертензивных препаратов были ингибиторы АПФ $(60,8 \%)$ и Аиуретики (60,2\%) (рис. 1$)$. Наиболее часто назначаемым ингибитором АПФ был энакаприм (22,3\%), на втором месте - периндоприл (18\%). Самым часто назначаемым БКК быц амлодипин (41\%), Аиуретиком инаапамиА (35\%).

Комбинированная терапия была представмена у 38,2\% больных Авухкомпонентными комбинациями; на Аолю трехкомпонентных комбинаций приходилось $34,2 \%$, 
Таблица 1. Характеристика пациентов, включенных в программу АОКАЗАТЕ $А$ СТВО $(\mathrm{n}=1599)$

\begin{tabular}{|c|c|}
\hline Параметр & Значение \\
\hline Мужчины & $621(38,8)$ \\
\hline Возраст, годы & $61,6 \pm 10$ \\
\hline - <50 мет, \% & 11,2 \\
\hline • $50-59$ мет, \% & 28,5 \\
\hline • 60-69 мет, \% & 38,3 \\
\hline • 70-79 мет, \% & 17,3 \\
\hline • $\geq 80$ мет, \% & 3,19 \\
\hline ИМТ, кг/м² & $29,5 \pm 4,7$ \\
\hline - $<25 \mathrm{\kappa r} / \mathrm{M}^{2}, \%$ & 17,2 \\
\hline - $25-29,9$ кг $/ \mathrm{M}^{2}, \%$ & 41,5 \\
\hline - $>30 \mathrm{Kr} / \mathrm{M}^{2}, \%$ & 40,7 \\
\hline Абдоминальное ожирение & $637(39,8)$ \\
\hline Курение & $324(20,3)$ \\
\hline Аислипидемия & $1068(66,8)$ \\
\hline Сахарный Аиабет & $307(19,2)$ \\
\hline ИБС & $636(39,8)$ \\
\hline Инсульт / ТИА в анамнезе & $141(8,9)$ \\
\hline $\mathrm{XCH}$ & $290(18,1)$ \\
\hline ЗПА & $132(8,3)$ \\
\hline Патология почек & $110(6,9)$ \\
\hline Алительность АГ, гоАы & $9,4(5,3 ; 16,3)$ \\
\hline СреАний возраст Аиагностики АГ, годы & $50,4 \pm 9$ \\
\hline \multicolumn{2}{|c|}{ 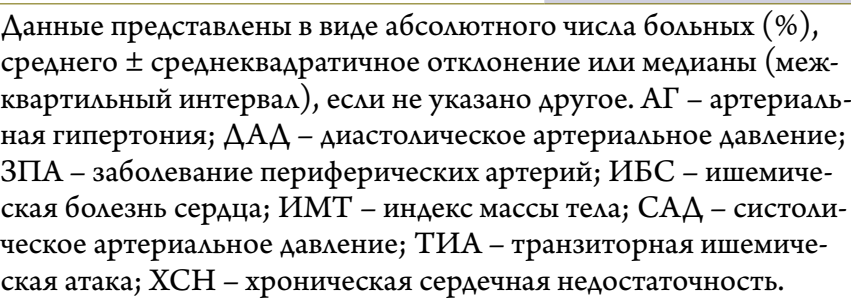 } \\
\hline
\end{tabular}

четырехкомпонентных - 13,1\%, пятикомпонентных $1,2 \%$. При этом, согласно Аанным ИРК, фиксированные комбинации получали мишь 226 (14,1\%) больных.

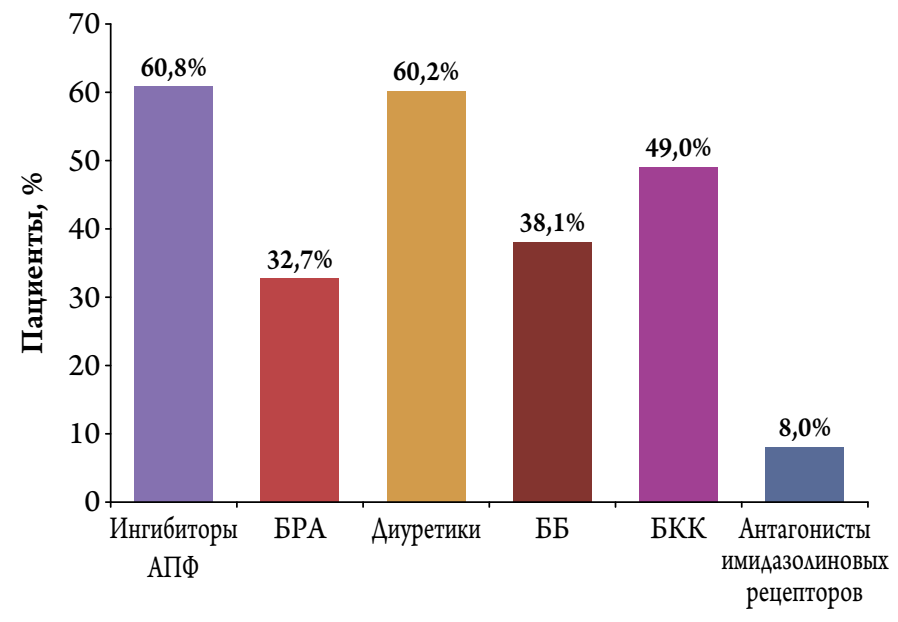

Рис. 1. Частота приема антигипертензивных препаратов разных кмассов переА вкАючением в программу.

ББ - $\beta$-адреноблокаторы; БКК - блокаторы камьциевых каналов; БРА - блокаторы рецепторов к ангиотензину II; АПФ - ангиотензинпревращающий фермент.

Следует отметить, что комбинацию ингибитора АПФ, БКК и Аиуретика покучали 288 (18\%) больных, а комбинацию периндоприма с амлодипином и индапамидом 77 (4,8\%). Распределение пациентов по количеству исходно принимаемых препаратов Аля кажАого Аиапазона АА в соответствии со степенью АГ преАставцено на рис. 2.

\section{АГТ в ходе исследования}

Максимальные и субмаксимальные дозы трипликсама были назначены 59,7\% пациентов: дозу 5/2,5 / 10 мг получали $33,7 \%$ пациентов, Аозу 10/2,5/10 мг - 23\%, дозу

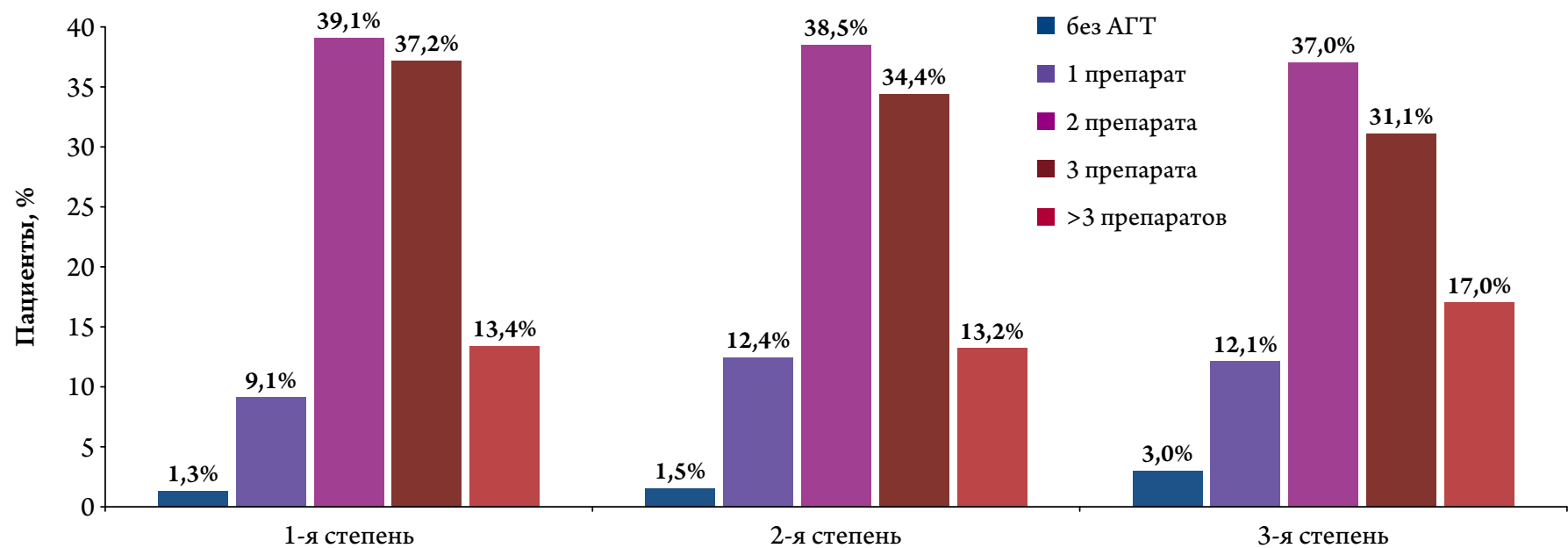

Рис. 2. Распределение пациентов в зависимости от исходного количества препаратов и степени артериамьной гипертонии.

АГТ - антигипертензивная терапия. На рисунке представлено процентное распределение пациентов в зависимости от количества антигипертензивных препаратов, принимаемых до включения в программу (от полного отсутствия АГТ до 3 и более препаратов разных классов). Аанные преАставлены раздельно Аля каждой степени АГ. 


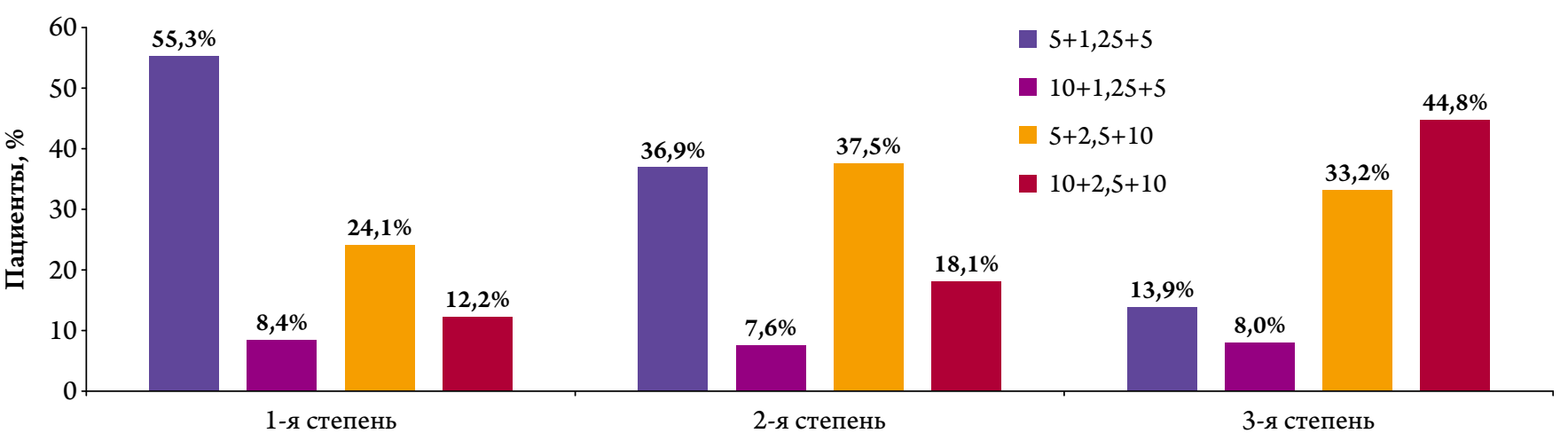

Рис. 3. Распределение пациентов в зависимости от дозы трипииксама и степени артериамьной гипертонии.

На рисунке преАставлено процентное распределение пациентов в зависимости от назначенной дозы трипликсама. Аанные преАставлены раздельно Аля кажАой степени АГ.

Таблица 2. Аоза трипликсама в зависимости от количества исходно принимаемых антигипертензивных препаратов

\begin{tabular}{l|ccc}
\multicolumn{1}{c}{ Аоза трипликсама, мг } & $\mathbf{2}$ группы препаратов & 3 группы препаратов & >3 групп препаратов \\
\hline $5 / 1,25 / 5$ & $42 \%$ & $27,1 \%$ & $19,2 \%$ \\
\hline $10 / 1,25 / 5$ & $7,4 \%$ & $8,6 \%$ & $6,1 \%$ \\
\hline $5 / 2,5 / 10$ & $34,8 \%$ & $36,9 \%$ & $31,9 \%$ \\
\hline $10 / 2,5 / 10$ & $15,9 \%$ & $27,4 \%$ & $42,8 \%$
\end{tabular}

5/1,25/5 мг - 35,5\%. Реже всего использовалась Аоза $10 / 1,25 / 5$ мг - у 7,8\%. На рис. 3 преАставлено распреАеление пациентов в зависимости от Аозы трипликсама по степеням АГ.

На выбор Аозы трипликсама влияло также количество препаратов, принимаемых пациентом Ао вкАючения в программу. Максимальная доза чаще всего назначалась пациентам, принимавшим более 3 препаратов, минимальная - пациентам, принимавшим 2 препарата и менее (табц.2).

У большинства пациентов Аоза трипликсама в ходе исследования оставалась стабильной. К моменту завершения программы Аозу 5/1,25/5 мг получали 32,7\%, Аозу $10 / 1,25 / 5$ мг - 7,5\%, Аозу 5/2,5/10 мг - 33,9\% и Аозу $10 / 2,5 / 10$ мг - 26\% пациентов. У небольшого числа пациентов отмечались некоторые изменения дозы: в основном повышение к визиту 2 и снижение к заключительному визиту.

В ходе исследования получали Аругую АГТ 50,6\% пациентов: бета-блокаторы (ББ) - 44,7\%, моксониАин - 7,1\%, Аиуретики - 2,9\%, БКК (верапамик) - 0,3\%, ингибитор АПФ (каптоприх при повышении АА) - 1,3\%.
$\beta$-ААреноблокаторы Аостоверно чаще назначались пациентам с исходно более высоким САА, исходно принимающим ББ или получающим 3 препарата и более, с анамнезом ИБС, ХСН, в отсутствие СА и с исходной ЧСС $>90$ уА/мин.

\section{Аинамика клинического АА в ходе исследования}

Анализ эффективности провеАен в группе из 1568 пациентов в связи с Аосрочным выбытием 31 человека. Аинамика клинического АА и ЧСС по визитам преАставмена в табл. 3. Уже через 2 неА после начала терапии трипликсамом отмечено достоверное снижение АА.

Абсолютное снижение САА в течение 3 мес приема трипликсама составило 37,9 ммрт.ст., ААА 17,9 мм рт. ст. Кроме того, отмечалось статистически значимое снижение ЧСС по мере снижения АА:

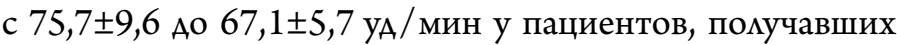
$\beta$-алреноблокаторы, и с $73,7 \pm 8,9$ Ао $69,0 \pm 5,7$ уА/мин у не получавших их. У пациентов, получавших только трипликсам, выраженность снижения АА не отличалась от таковой у пациентов, получавших Аополнительную

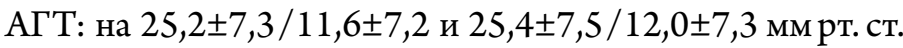

Таблица 3. Аинамика АА и ЧСС на фоне приема трипликсама $(\mathrm{n}=1568)^{*}$

\begin{tabular}{l|cccc}
\multicolumn{1}{r}{ Показатемь } & Исхонно & $\mathbf{2}$ неА & 1 мес & 3 мес \\
\hline САА, мм рт. ст. & $165,5 \pm 15,3$ & $142,6 \pm 13,5$ & $132,8 \pm 10,9$ & $127,6 \pm 8,5$ \\
\hline AАА, мм рт. ст. & $96,2 \pm 9,7$ & $85,3 \pm 8,2$ & $80,6 \pm 7,2$ & $78,3 \pm 6,4$ \\
\hline ЧСС, уА/мин & $74,6 \pm 9,3$ & $70,8 \pm 6,9$ & $69,2 \pm 6,3$ & $68,1 \pm 5,8$ \\
\hline
\end{tabular}

Аанные преАставлены в виде $\mathrm{M} \pm \mathrm{SD}$. * - p<0,01 для кажАого последующего значения по сравнению с предыдущим и исходным.

ААА - Аиастолическое артериальное Аавление; САА - систолическое артериальное Аавление; ЧСС - частота сердечных сокращений. 


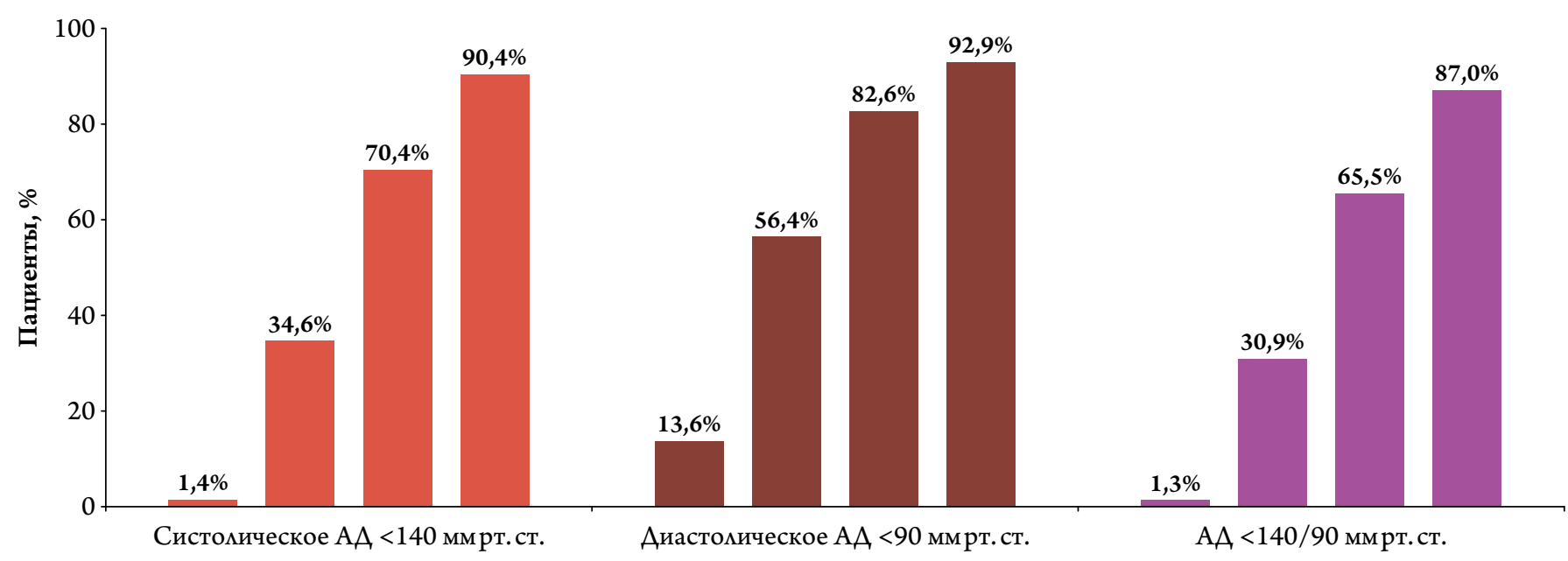

Рис. 4. Аоля пациентов, Аостигших целевого артериального Аавмения от визита 1 к визиту 4 на фоне приема трипликсама.

АА - артериальное Аавление; кажАые 4 столбца диаграммы в каждой категории соответствуют визитам в клинику (с первого по четвертый соответственно). Рисунок отображает процент пациентов, Аостигших целевого систолического АА $<140$ мм рт. ст., Аиастолического АА <90 мм рт. ст. или АА < 140/90 мм рт. ст. на первом, втором, третьем и четвертом визитах.

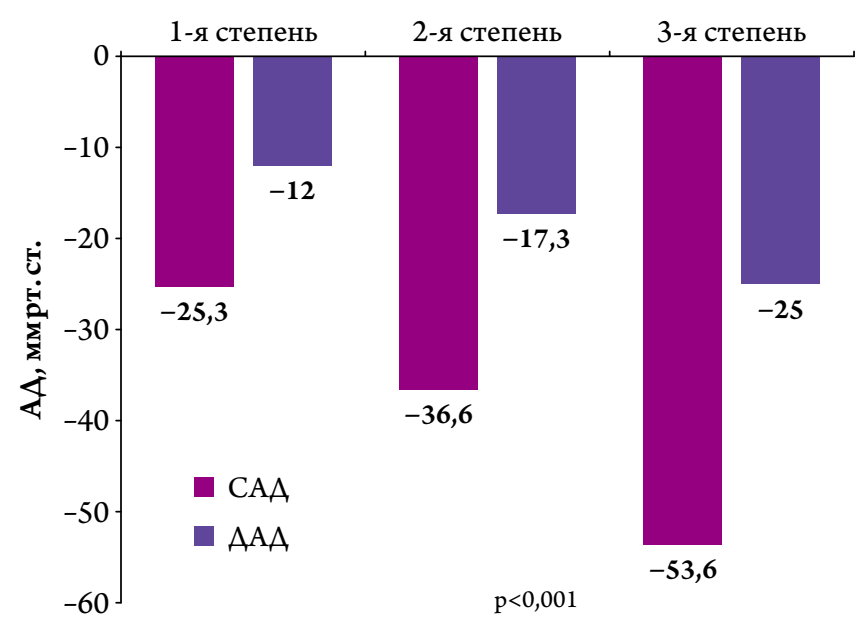

Рис. 5. Выраженность снижения АА в зависимости от уровня АА при вкАючении в программу.

3Аесь и на рис. 6: АА - артериальное Аавление; ААА - Аиастолическое АА; САА - систолическое АА.

Амя АГ 1-й степени, на $35,2 \pm 9,0 / 17,3 \pm 8,2$ и $36,4 \pm 9,4 /$ $17,3 \pm 8,1$ мм рт. ст. ААя АГ 2-й степени и на $52,7 \pm 15,3$ / $25,1 \pm 10,6$ и $53,5 \pm 15,3 / 25,0 \pm 10,8$ ммрт. ст. ААя АГ 3-й степени. Уже через 2 неА посме начама приема трипликсама целевого AА <140/90 мм рт.ст. Аостигли почти $1 / 3$ пациентов, через $1 \mathrm{мес-} \mathrm{более} 50 \%$ пациентов, через 3 мес - более $85 \%$ (рис. 4). Примечательно, что к концу исследования $25,4 \%$ пациентов Аостигли уровня клинического AA < $130 / 80$ мм рт. ст.

Следует отметить, что среАи 774 пациентов, которым трипликсам был назначен без Аополнительной терапии, у 684 (88,4\%) был достигнут цемевой уровень AА. СреАи пациентов, принимавших дополнительные антигипертензивные препараты $(\mathrm{n}=794)$, цели достигми $85,6 \%$. Анализ эффективности трипликсама в зави-

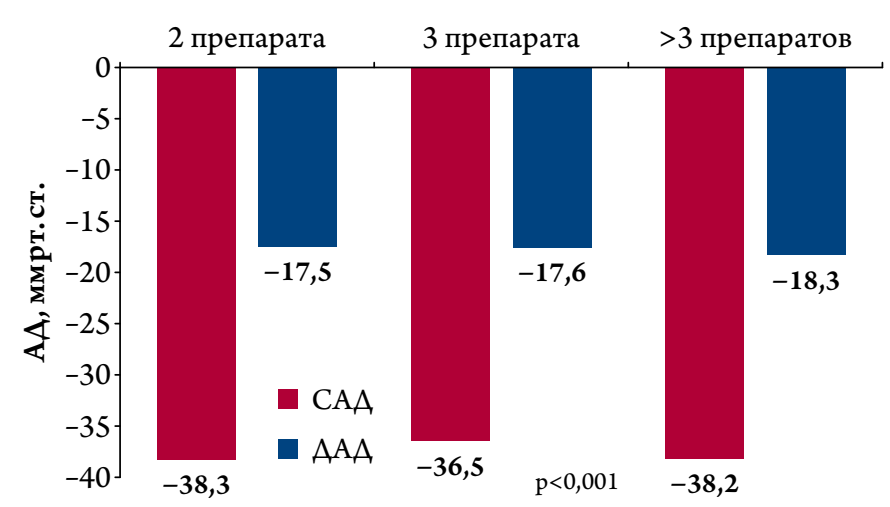

Рис. 6. Снижение AА в зависимости от количества антигипертензивных препаратов при вкмючении в программу.

симости от уровня АА при включении и количества исходно принимаемых препаратов продемонстрировал его высокую эффективность во всех диапазонах (рис. 5, 6).

Через 3 мес мечения целевого АА Аостигли 97,1\% больных с исходной 1-й степенью повышения АА, 88,8\% со 2-й и 73,5\% - с 3-й. Количество препаратов, принимаемых до назначения трипликсама, также не влияло на частоту достижения целевого АА: 87,1\% Аля Авухкомпонентной терапии, 85,9\% - Амя трехкомпонентной и $86,8 \%$ Амя пациентов, получавших более 3 препаратов разных групп. Аинамика AА в зависимости от групп препаратов, принимаемых до начала программы, преАставлена в таблице 4. Следует отметить, что Ааже среди пациентов, исходно принимавших комбинацию ингибитора АПФ, БКК и Аиуретика, назначение трипликсама без Аополнительной терапии привело к снижению АА на $32,4 \pm 12,2$ / $16,0 \pm 10,1$ мм рт.ст. Примечательно, что уже через 2 неА 
Таблица 4. Аинамика клинического АА в зависимости от исходной терапии

\begin{tabular}{lcccc}
\multicolumn{1}{c}{ Группы пациентов } & $\mathbf{N}$ & Снижение САА & Снижение ААА \\
\hline иАПФ+Аиуретик & 177 & $37,5 \pm 12,4(36)$ & $17,7 \pm 9,7(18)$ \\
\hline иАПФ+БКК & 124 & $37,4 \pm 13,4(35)$ & $16,6 \pm 9,3(18)$ \\
\hline БРА+Аиуретик & 102 & $40,7 \pm 15,3(40)$ & $19,8 \pm 9,9(20)$ \\
\hline БРА+БКК & 60 & $40,0 \pm 16,6(40)$ & $17,2 \pm 8,4(20)$ \\
\hline иАПФ+БКК+Аиуретик & 166 & $33,0 \pm 12,1(32)$ & $15,7 \pm 9,5(15)$ \\
\hline БРА+БКК+Аиуретик & 67 & $35,4 \pm 16,0(34)$ & $18,1 \pm 11,7(20)$ \\
\hline
\end{tabular}

БКК - блокатор кальциевых каналов; БРА - блокатор рецепторов к ангиотензину II; иАПФ - ингибитор ангиотензинпревращающего фермента, САА - систолическое АА, ААА - Аиастолическое АА.

Таблица 5. Аинамика амбулаторного АА на фоне применения трипииксама $(\mathrm{n}=420)$

\begin{tabular}{lccc}
\multicolumn{1}{c}{ Показатемь } & $\mathbf{2 ~ н е А ~}$ & $\mathbf{1}$ мес & $\mathbf{3}$ мес \\
\hline САА утро, мм рт.ст. & $146,8 \pm 13,0$ & $134,4 \pm 10,5^{*}$ & $128,6 \pm 9,0^{* *}$ \\
\hline САА вечер, мм рт.ст. & $145,2 \pm 12,8$ & $134,6 \pm 10,0^{*}$ & $129,2 \pm 8,5^{* *}$ \\
\hline ААА утро, мм рт.ст. & $86,4 \pm 7,8$ & $80,8 \pm 6,5^{*}$ & $78,2 \pm 5,6^{* *}$ \\
\hline ААА вечер, мм рт.ст. & $85,6 \pm 7,6$ & $80,7 \pm 6,4^{*}$ & $78,3 \pm 5,6^{* *}$ \\
\hline
\end{tabular}

Аанные преАставлены в виде $\mathrm{M} \pm \mathrm{SD} .^{*}$ - $\mathrm{p}<0,001$ по сравнению с визитом через 2 неА; ${ }^{* *}-\mathrm{p}<0,001$ по сравнению с визитом через 1 мес.

ААА - Аиастолическое артериальное Аавление; САА - систолическое артериальное Аавление.

мечения на терапию ответили 1513 (96,5\%) пациентов, а к завершающему визиту их было 1567 (99,9\%), т.е. из 1568 человек, завершивших исследование, не ответил на мечение мишь оАин.

\section{Аинамика амбулаторного АА в ходе исследования}

Из 1568 пациентов, завершивших исследование, у 420 уаалось получить Аневники самоконтромя АA, заполненные в соответствии с протоколом. В этой группе была проанамизирована эффективность трипликсама в отношении амбуматорного АА (табц.5). Отмечено Аостоверное снижение САА и ААА от визита к визиту. Целевого АА <135/85 ммрт.ст. к визиту 2 Аостигли $11,2 \%$, к визиту 3 - 43,1\%, а к визиту 4 - 68,1\% пациентов. Кроме того, у всех пациентов отмечалось Аостоверное снижение ЧСС к послеАнему визиту $(67,9 \pm 5,2$ и $71,4 \pm 6,7$ уА/мин утром и $69,1 \pm 5,3$ и $72,2 \pm 6,4$ уА/мин вечером соответственно; $\mathrm{p}<0,001)$.

\section{Трипликсам и приверженность клечению}

Применение трипликсама сопровожАалось Аостоверным повышением среАней оценки анкеты при-

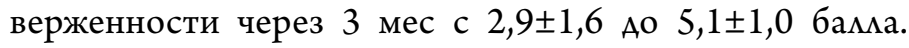
При этом число пациентов с хорошей приверженностью, набравших 6 и 5 бамлов, увеличимось с 6,9 до 38\% и с 10 до $36,6 \%$ соответственно, а число пациентов без приверженности, набравших $\leq 3$ бамлов, сократилось с 65,8 Ао 6,1\% (p<0,001). СреАний бамл оценки эффективности мечения врачами составим 9,7 $\pm 0,9,88,3 \%$ врачей были полностью удовлетворены результатами мечения и поставили максимальную оценку. Аля пациентов

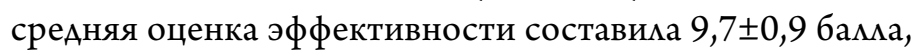

а полностью УАовлетворены мечением были 50,2\% пациентов. Следует отметить, что $38,8 \%$ пациентов не оценивали эффективность.

\section{Переносимость и нежелательные явления}

Терапия трипликсамом хорошо переносилась пациентами. Из 1599 пациентов, которым быи назначен препарат, выбыл 31 (1,9\%), из них в связи с нежелатемьными явлениями (НЯ) - 5. СреАи остальных причин выбывания быми отказ $(n=5)$, несоблюдение режима приема препарата $(\mathrm{n}=2)$, финансовые причины $(\mathrm{n}=5)$. В 14 случаях причина прекращения участия в исследовании не указана. В общей сложности НЯ зафиксированы у 8 пациентов. Отмечено 2 серьезных НЯ - госпитализация с жекудочно-кишечным кровотечением и провеАение аортокоронарного шунтирования (АКШ). Оба пациента Аосрочно выбыли из исследования. В обоих случаях причинно-следственная связь с приемом трипликсама не прослеживается. Пациент с АКШ, очевиАно, бым включен в исследование по ошибке, так как о запланированной операции Аолжно бымо быть известно заранее. Из несерьезных НЯ наиболее частыми быми отеки нижних конечностей (табл.6). При этом

Таблица 6. Нежелательные явмения при назначении трипликсама

\begin{tabular}{l|c}
\multicolumn{1}{c}{ Нежематемьное явмение } & Абс. число \\
\hline Отеки голеней & 3 \\
\hline Артериальная гипотония & 1 \\
\hline Слабость & 1 \\
\hline Головокружение & 2 \\
\hline Гомовная боль & 2 \\
\hline Тахикардия & 1
\end{tabular}


Таблица 7. Влияние трипииксама на основные биохимические показатеки

\begin{tabular}{|c|c|c|c|c|}
\hline Параметр & Число больных & ИСХОАНО & Через 3 мес & $\mathbf{p}$ \\
\hline OХC, ммомь $/ \Lambda$ & 822 & $5,9 \pm 1,2$ & $5,0 \pm 0,9$ & $<0,001^{*}$ \\
\hline 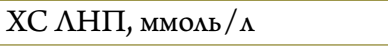 & 530 & $3,3 \pm 1,0$ & $2,6 \pm 0,8$ & $<0,001^{*}$ \\
\hline ТГ, ммомь / & 531 & $1,9 \pm 1,2$ & $1,6 \pm 0,6$ & $<0,001^{*}$ \\
\hline ХС $\Lambda$ ВП, ммоль $/ \Lambda$ & 430 & $1,3 \pm 0,6$ & $1,5 \pm 0,5$ & $<0,001^{*}$ \\
\hline ГАюкоза, ммоль / & 723 & $5,7 \pm 1,1$ & $5,4 \pm 0,9$ & $<0,001^{*}$ \\
\hline $\mathrm{HbA}_{1 \mathrm{c}}, \%$ & 209 & $5,8 \pm 1,1$ & $5,6 \pm 0,9$ & $<0,001^{*}$ \\
\hline Креатинин, мкмомь /А & 595 & $88,0 \pm 15,8$ & $84,8 \pm 14,1$ & $<0,001^{*}$ \\
\hline СКФ, мА/мин/1,73 м² & 303 & $71,3 \pm 20,0$ & $75,3 \pm 19,0$ & $<0,001^{*}$ \\
\hline Мочевая кисмота, мкмоль / & 347 & $314,6 \pm 94,2$ & $295,8 \pm 84,2$ & $<0,001^{*}$ \\
\hline
\end{tabular}

ХС $\Lambda$ ВП - холестерин мипопротеинов высокой плотности; ХС $\Lambda$ НП - холестерин липопротеинов низкой плотности; ОХС - общий холестерин; СКФ - скорость клубочковой фильтрации; ТГ - триглицериды; $\mathrm{Hb}_{1 \mathrm{c}}$ - гликированный гемоглобин.

3 пациента завершили программу в соответствии с протоколом, несмотря на НЯ. Сведения о Аинамике отдельных биохимических параметров имелись не у всех пациентов. Назначение трипликсама сопровожАалось достоверным укучшением ряда метаболических параметров, функции почек и не влияло на уровень эмектролитов в крови (табл. 7).

\section{Обсужаение}

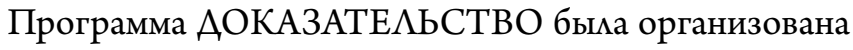
А^я оценки антигипертензивной эффективности и безопасности фиксированной комбинации амлодипин/индапамиА/периндоприла аргинин (трипликсам, оригинальный препарат «Servier») и ее влияния на приверженность пациентов к мечению. Замысел исследования обосновывался необходимостью продемонстрировать возможности современной АГТ с использованием трехкомпонентной фиксированной комбинации у широкого круга больных АГ, получающих различные схемы мечения.

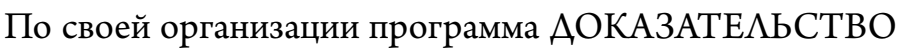
относится к исследованиям клинической практики, т.е. выполняется врачами, не имеющими специальной подготовки. Регистрационная карта быма дополнена специальными опросниками по оценке эффективности мечения и приверженности.

Популяция пациентов, вкмюченных в программу

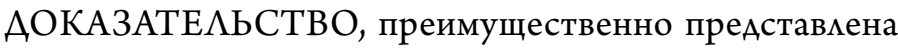
мицами в возрасте от 50 до 69 мет, почти $2 / 3$ - женщины с преобладанием АГ 2-й и 3-й степени и наличием факторов риска. Характеристика попукяции сходна с Аругими отечественными и зарубежными исследованиями клинической практики [21-28] и отражает состав амбулаторных пациентов терапевтического и кардиологического профиля. В протоколе исследования не было заложено ограничений по исходному уровню АА и получаемой АГТ, что привело к включению пациентов с контролируемой АГ $(1,3 \%)$ или не получающих терапию $(1,8 \%)$. Тем не менее большинство пациентов характеризовалось отсутствием контромя АА, а $87,4 \%$ получали 2 антигипертензивных препарата и более. В целом ингибиторы АПФ, Аиуретики и БКК были мидерами по назначению. Анализ мечения до включения продемонстрировац низкую частоту использования фиксированных комбинаций $(14,3 \%)$, что отчасти можно объяснить подходом к заполнению ИРК: врачам преАлагалось указывать не название препарата, а все его составляющие отдельно. Можно преАположить, что многие забывали при этом отметить, что препарат входит в состав фиксированной комбинации. СреАи указанных фиксированных комбинаций мидировало сочетание БРА и тиазидных Аиуретиков $(6,2 \%)$; на втором месте была комбинация ингибитора АПФ с Аиуретиком $(4,8 \%)$. На Аолю комбинаций ингибитора АПФ, БКК и Аиуретика пришлось $18 \%$, а комбинированный препарат периндоприла аргинина с амкодипином и индапамидом получали $4,8 \%$. Кроме того, можно отметить достаточно высокую частоту назначения $\beta$-адреноблокаторов $(38,1 \%)$.

Большинству пациентов трипликсам был назначен в качестве замены двух- и трехкомпонентной терапии, при этом каждому второму врачи назначали его без Аополнительных препаратов. Аиапазон Аозировок препарата позволил врачам эффективно подбирать дозы отАельных компонентов, при этом почти $2 / 3$ пациентов были назначены максимальные и субмаксимальные дозы трипликсама. Большинству не потребовалось изменение дозы в ходе исследования или назначение дополнительных препаратов.

Прием трипликсама сопровожАался быстрым развитием антигипертензивного эффекта: основное снижение CAA/AAA на 22,9/10,9 мм рт. ст. отмечено уже через 2 неА с Аостижением целевого АA почти у $1 / 3$ больных. В Аальнейшем отмечалось постепенное нарастание антигипертензивного эффекта: через 3 мес АА снизи- 
мось на 38/18 мм рт. ст., а целевого АА Аостигли почти $90 \%$ больных. При этом антигипертензивный эффект практически не зависел от количества исходно принимаемых препаратов и отмечался в том числе у пациентов, ранее получавших ингибитор АПФ в комбинации с БКК и Аиуретиком. Сопоставимый антигипертензивный эффект трипликсама в клинической практике был ранее отмечен в украинской программе ТРИУМФ с включением 1213 пациентов с неконтролируемой АГ [28]. Кроме того, схожая эффективность комбинации перинАоприла аргинин/индапамид/амлодипин отмечена в трех зарубежных исследованиях с похожим дизайном [24-26]. Важно подчеркнуть, что препарат быц эффективен во всем диапазоне исходного АА: цель Аостигнута у 74\% пациентов с исходным АA >180/110 мм рт. ст. Анализ изменений амбулаторного АА подтвердим высокую эффективность препарата (цемевое АА Аостигнуто у $2 / 3$ больных), а равномерное снижение АА в утренние и вечерние часы свидетельствует о стабильности антигипертензивного эффекта.

После публикации результатов исследования SPRINT [29] и выхода в 2017 г. новых американских рекомендаций по мечению АГ [30] большой интерес преАставмяют возможности фиксированных комбинаций в отношении достижения жесткого контроля АА с уровнем $<130 / 80$ мм рт. ст. Примечательно, что применение трипликсама сопровожАалось достижением этих значений у кажАого четвертого пациента.

Information about the author:

RUDN University, Moscow Russia

Kobalava Zhanna D. - MD, PhD, professor.

E-mail: zkobalava@mail.ru

\section{МИТЕРATУPA/REFERENCES}

1. Muromtseva G.A., Kontsevaya A.V., Konstantinov V.V. et al. The prevalence of non-infectious diseases risk factors in Russian population in 2012-2013 years. The results of ECVD-RF. Cardiovascular Therapy and Prevention 2014;13 (6):4-11. Russian (Муромцева Г.А., Концевая А.В., Константинов В.В. и Ар. Распространенность факторов риска неинфекционных заболеваний в российской популяции в 2012-2013 гг. Результаты исслеАования ЭССЕ-РФ. КарАиоваскумярная терапия и профилактика 2014;13 (6):4-11). DOI: 10.15829/1728-8800-2014-6-4-11

2. Prugger C., Keil U., Wellmann J. et al. Blood pressure control and knowledge of target blood pressure in coronary patients across Europe: results from the EUROASPIRE III survey. J Hypertens 2011;29 (8):1641-1648. DOI: 10.1097/HJH. 0b013e328348efa7

3. Lozano R., Naghavi M., Foreman K. et al. Global and regional mortality from 235 causes of death for 20 age groups in 1990 and 2010: a systematic analysis for the Global Burden of Disease Study 2010. Lancet 2012;380 (9859):2095-2128. DOI: 10.1016/S0140-6736 (12) 61728-0.

4. Wald D.S., Law M., Morris J.K. et al. Combination Therapy Versus Monotherapy in reducing blood pressure: meta-analysis
Аостижение целевого АА в ходе исследования сопровожАалось небольшим, но Аостоверным снижением ЧСС, независимо от приема $\beta$-адреноблокаторов. Таким образом, несмотря на то что частота приема $\beta$-адреноблокаторов в ходе исследования увеличилась с 38,7 до 44,7\%, можно преАполагать, что отчасти снижение ЧСС стало слеАствием снижения АА.

Аечение трипликсамом хорошо переносилось пациентами и сопровожАалось значительным повышением приверженности к мечению. Можно отметить крайне низкую частоту развития отеков, несмотря на то что кажАый пятый пациент получал максимальные дозы амлодипина в составе комбинации.

\section{Закиючение}

Оптимизация терапевтического режима с использованием фиксированной комбинации амкодипина/индапамида/периндоприла аргинина - трипликсама привоАит к снижению клинического артериального давления на 38/18 мм рт. ст. и позволяет быстро Аостичь контроля артериальной гипертонии у большинства больных, способствуя значительному повышению приверженности к антигипертензивной терапии. Высокая эффективность во всем Аиапазоне повышения артериального Аавмения, благоприятные метаболические свойства, хорошая переносимость и безопасность трипликсама открывают новые горизонты в мечении больных артериальной гипертонией.

on 11,000 participants from 42 trials. Am J Med 2009;122 (3):290300. DOI: $10.1016 / j$. amjmed. 2008.09.038

5. Corrao G., Parodi A., Zambon A. et al. Reduced discontinuation of antihypertensive treatment by two-drug combination as first step. Evidence from daily life practice. J Hypertens 2010;28 (7):15841590. DOI: $10.1097 /$ HJH. 0b013e328339f9fa

6. Gupta A.K., Arshad S., Poulter N.R. Compliance, safety, and effectiveness of fixed-dose combinations of antihypertensive agents: a meta-analysis. Hypertension 2010;55 (2):399-407. DOI: 10.1161/HYPERTENSIONAHA. 109.139816

7. Chalmers J., Arima H., Harrap S. et al. Global survey of current practice in management of hypertension as reported by societies affiliated with the International Society of Hypertension. J Hypertens 2013;31 (5):1043-1048. DOI: 10.1097/HJH. 0b013e32835f7eef. 8. Mancia G., Fagard R., Narkiewicz K. et al. 2013 ESH/ESC Guidelines for the management of arterial hypertension: The Task Force for the management of arterial hypertension of the European Society of Hypertension (ESH) and of the European Society of Cardiology (ESC). J Hypertens 2013;31 (7):1281-1357. DOI: 10.1097/01. hjh. 0000431740.32696. cc 
9. Russian society of arterial hypertension/Russian society of cardiology. Diagnosis and treatment of arterial hypertension. Russian guidelines. Systemic Hypertension 2010;3:5-26. Russian (Российское медицинское общество по артериальной гипертонии (РМОАГ), Всероссийское научное общество кардиологов (ВНОК). Аиагностика и мечение артериальной гипертензии. Российские рекоменАации (четвертый пересмотр). Системные гипертензии 2010;3:5-26).

10. Chazova I.E., Oshepkova E.V., Zhernakova Yu.V. Diagnostics and treatment of arterial hypertension (Clinical guidelines). Kardiologicheskij Vestnik 2015;10 (1):5-30. Russian (Чазова И.Е., Ощепкова Е.В., Жернакова Ю.В. Аиагностика и мечение артериальной гипертонии (Клинические рекомендации). КарАиологический вестник 2015;10 (1):5-30).

11. https: / / www.escardio.org / The-ESC / Press-Office / Pressreleases / first-look-at-the-new-2018-european-guidelines-for-thetreatment-of-high-blood-p

12. Williams B., Lacy P.S., Thom S.M. et al. Differential impact of blood pressure-lowering drugs on central aortic pressure and clinical outcomes. Principal results of the Conduit Artery Function Evaluation (CAFE) study. Circulation 2006;113 (9):1213-1225. DOI: 10.1161 /CIRCULATIONAHA. 105.595496

13. Rodriguez-Granillo G.A., Vos J., Bruining N. et al. Long-term effect of perindopril on coronary atherosclerosis progression (from the perindopril's prospective effect on coronary atherosclerosis by angiography and intravascular ultrasound evaluation [PERSPECTIVE] study). Am J Cardiol 2007;100 (2):159-163. DOI: $10.1016 /$ j.amjcard. 2007.02.073

14. Ceconi C., Fox K.M., Remme W.J. et al. ACE inhibition with perindopril and endothelial function. Results of a substudy of the EUROPA study: PERTINENT. Cardiovasc Res 2007;73 (1):237-246. DOI: 10.1016/j. cardiores. 2006.10.021

15. Pitt B., Byington R.P., Furberg C.D. et al. Effect of amlodipine on the progression of atherosclerosis and the occurrence of clinical events. PREVENT Investigators. Circulation 2000;102 (13):15031510.

16. Dahlof B., Sever P. S., Poulter N.R. et al. Prevention of cardiovascular events with an antihypertensive regimen of amlodipine adding perindopril as required versus atenolol adding bendroflumethiazide as required, in the Anglo-Scandinavian Cardiac Outcomes Trial (ASCOT-BPLA): a multicenter randomized controlled trial. Lancet 2005;366 (948):895-906. DOI: 10.1016/S0140-6736 (05) 67185-1.

17. Leenen F.H., Nwachuku C.E., Black H.R. et al. Clinical events in high-risk hypertensive patients randomly assigned to calcium channel blocker versus angiotensin-converting enzyme inhibitor in the antihypertensive and lipid-lowering treatment to prevent heart attack trial. Hypertension 2006;48 (3):374-384. DOI: 10.1161/01. HYP. 0000231662.77359. de

18. PROGRESS Collaborative Group. Randomized trial of a perindopril-based blood-pressure-lowering regimen among 6,105 individuals with previous stroke or transient ischaemic attack. Lancet 2001;358 (9287):1033-1041. DOI: 10.1016/S0140-6736 (01) 06178-5

19. Bulpitt C. J., Beckett N. S., Cooke J. et al. Results of the pilot study for the Hypertension in the Very Elderly Trial.J Hypertens 2003;21 (12):2409-2417. DOI: 10.1097/01. hjh. 0000084782.15238. a2

20. Chalmers J., Arima H., Woodward M. et al. Effects of combination of perindopril, indapamide, and calcium channel blockers in patients with type 2 diabetes mellitus: results from the Action In Diabetes and Vascular Disease: Preterax and Diamicron Controlled Evaluation (ADVANCE) trial. Hypertension 2014;63 (2):259-264. DOI: 10.1161/HYPERTENSIONAHA. 113.02252
21. Lopatin Y.M., Kobalava Z.D., Kislyak O.A. et al. Ways of optimizing control of arterial hypertension. Main results of scientific program ARGUS-2. Clinical Pharmacology and Therapy 2007;16 (2):40-46. Russian (Иопатин Ю.М., Кобамава Ж.А., Кисляк О.А. и Ар. Пути улучшения контроля артериальной гипертонии. Основные результаты российской научно-практической программы АРГУС-2. Клиническая фармакология и терапия 2007;16 (2):40-46).

22. Karpov Yu.A., Deev A.D. Uncontrolled Arterial Hypertension New Possibilities in Solving Problems of Increasing the Effectiveness of Treatment. Kardiologiya 2012;52 (2):29-35. Russian (Карпов Ю.А., Аеев А.А. от имени врачей - участников программы «ПРОРЫВ». Неконтролируемая артериальная гипертония - новые возможности в решении проблемы повышения эффективности мечения. Кардиология 2012;52 (2):29-35).

23. Kobalava Zh.D., Kotovskaya Yu. V., Lukyanova E.A. Combined Therapy of Arterial Hypertension With thse Fixed Combination of Perindopril Arginine/Amlodipine in Real Clinical Practice: the Organization and the Main Results of the Program CONSTANTA. Kardiologiya 2013;53 (6):25-34. Russian (Кобалава Ж.А., Котовская Ю.В., Аукьянова Е.А. Комбинированная терапия артериальной гипертонии с использованием фиксированной комбинации периндоприла аргинина/амлодипина в реальной кАинической практике: организация и основные результаты программы КОНСТАНТА. КарАиология 2013;53 (6):25-34).

24. Tóth K., PIANIST Investigators. Antihypertensive efficacy of triple combination perindopril/indapamide plus amlodipine in high-risk hypertensives: results of the PIANIST study (Perindopril-Indapamide plus AmlodipiNe in high rISk hyperTensive patients). Am J Cardiovasc Drugs 2014;14 (2):137-145. DOI: 10.1007/s40256-014-0067-2.

25. Páll D., Szántó I., Szabó Z. Triple combination therapy in hypertension: the antihypertensive efficacy of treatment with perindopril, amlodipine, and indapamide SR. Clin Drug Investig 2014;34 (10):701-708. DOI: $10.1007 / \mathrm{s} 40261-014-0223-0$

26. Abraham G., Dezsi C. The Antihypertensive Efficacy of the Triple Fixed Combination of Perindopril, Indapamide, and Amlodipine: The Results of the PETRA Study. Adv Ther 2017;34 (7):17531763. DOI: $10.1007 /$ s12325-017-0572-1

27. Nedogoda S., Stojanov V. Single-Pill Combination of Perindo pril/Indapamide/Amlodipine in Patients with Uncontrolled Hypertension: A Randomized Controlled Trial. Cardiol Ther 2017;6 (1):91-104. DOI: 10.1007/s40119-017-0085-7

28. Lutay M.I., on behalf of the TRIUMF multicenter study group. Efficiency of the combined treatment of arterial hypertension in Ukraine: results of the TRIUMF multicenter study. 2016;4:1728. Russian (Иутай М.И. от имени многоцентровой исследовательской группы TRIUMF. Эффективность комбинированного мечения артериальной гипертензии в Украине: результаты многоцентрового исследования TRIUMF 2016;4:17-28).

29. SPRINT Research Group, Wright J.T. Jr, Williamson J.D., Whelton P. K. et al. A Randomized Trial of Intensive versus Standard Blood-Pressure Control. N Engl J Med 2015;373 (22):2103-2116. DOI: 10.1056/NEJMoa1511939

30. Whelton P. K., Carey R. M., Aronow W. S. et al. 2017 ACC/AHA/ AAPA / ABC / ACPM / AGS / APhA / ASH / ASPC / NMA / PCNA Guideline for the Prevention, Detection, Evaluation, and Management of High Blood Pressure in Adults. A Report of the American College ofCardiology/American Heart Association Task Force on Clinical Practice Guidelines. Hypertension 2018;71 (6):1269-1324. DOI: 10.1161/HYP. 0000000000000066

Поступима 10.05.18 (Received 10.05.18) 